\title{
A depressão em humanos e outras espécies*
}

\section{Depression across the Species}

\author{
Álvaro Machado Dias** \\ Doutorando do Departamento de Neurociências e Comportamento do Instituto de \\ Psicologia da Universidade de São Paulo, IP-NEC-USP, São Paulo, SP, Brasil
}

\begin{abstract}
RESUMO
Contexto: Este artigo possui dois objetivos associados. Primeiramente, revisa a literatura atual relativa aos modelos animais de depressão humana, usando técnicas de 'data mining' (mineração de dados). Subseqüentemente, discute se seria razoável estender o conceito de depressão a não humanos. Resultados: $O$ uso de modelos animais de depressão cresceu consideravelmente nos últimos anos, em associação com o desenvolvimento de novas drogas e novos estudos genéticos. Todavia, a possibilidade de se assumir uma correlação forte entre a depressão humana e o humor diminuído em outras espécies permanece incerta. A depressão humana representa um 'ponto de chegada' tanto em nível orgânico quanto fenomenológico; nosograficamente, ela só pode ser delineada dentro de um horizonte de possibilidades diagnósticas representadas pelas desordens alternativas com as quais a depressão compartilha aspectos.
\end{abstract}

Palavras-chave: Depressão, etiologia, evolução, humanos, animais.

\begin{abstract}
Backgrounds: this article has two close related goals. First it reviews the current literature on animal models of depression, using data mining techniques. Second it discusses whether it is feasible or not to extend the concept of depression to non-humans. Results: the use of animal models of depression increased dramatically over the last years, in association with the development of new drugs and genetic studies. On the other hand, the possibility to assume a strong correlation between human depression and low mood in other mammals remains unfeasible. Human depression represents a 'reaching-point', both at the organic and the phenomenological levels; nosographically, it can be asserted only within the horizon of possibilities represented by alternative disorders with which it shares common features.
\end{abstract}

Keywords: Depression, etiology, evolution, humans, animals.

\section{I ntrodução}

A depressão é uma séria desordem primariamente associada ao humor diminuído e secundariamente associada a outros sintomas (LEWIS, 1934). Apesar do fato de que a história da psicopatologia compreende uma grande diversidade de métodos, é de se ter em 
vista que a maioria dos cientistas e clínicos atualmente adota uma das seguintes concepções: ou a desordem é concebida desde um prisma descritivo-fenomenológico, tal como no DSM; ou o diagnóstico da desordem é intrinsecamente associado a hipóteses etiológicas, tal como no manual do CID (para uma revisão e discussão deste ponto, ver: Parshall e Priest, 1993).

Sob um enfoque descritivo, atualmente desponta a tendência de se diagnosticar e tratar 'animais com depressão', sob preceitos similares aos humanos. A despeito do fato de que esta pode ser considerada uma abordagem pragmaticamente válida para enfrentar o problema do sofrimento de animais em cativeiro, ela levanta algumas questões relativas à extensão e aos limites do conceito de depressão, que se fazem irredutíveis ao isomorfismo sintomatológico.

Tal como é de se notar, o princípio de organização por similaridade em que se baseiam as atuais abordagens descritivas tem como pressuposto a unidade da espécie e, portanto, a assunção de convergências de nível profundo (genética e epigênese) e nível proximal (cérebro e comportamento). Neste sentido conclui-se que, independentemente do paradigma nosográfico utilizado, as possibilidades analíticas de uma nosografia interespecífica implicam correlações em ambos os níveis, entre as espécies prospectadas.

Passando à análise destas correlações ao longo da história, faz-se notável que as perspectivas canônicas despontam dos modelos animais de depressão humana (em oposição aos modelos de depressão animal, propriamente ditos), tal como primeiramente sistematizados por Mckinney e Bunney (1969). De acordo com estes autores, a validade de tais modelos seria diretamente proporcional à presença de similaridades comportamentais (i.e. padrões de manifestação do humor diminuído), biológicas (i.e. semelhanças genéticas) e reversão por tratamentos aplicados a humanos (à extensão com que estes funcionam entre nós).

Ainda que estas categorias permaneçam válidas em nível geral, é de se ter em vista que os paradigmas experimentais de quarenta anos atrás eram menos multifacetários do que os da atualidade. Por exemplo, não é de se esperar que um modelo animal dotado de diversas e severas mutações genéticas, passíveis de afetar a sinalização cerebral, apresente respostas duradouras a qualquer tipo de tratamento. Neste sentido, dir-se-ia que os modelos animais da atualidade são categoricamente divididos de acordo com as funções que devem exercer: o modelo utilizado para testar o papel de um gene não é necessariamente o mesmo que será utilizado para testar a eficácia de um tratamento e assim por diante.

Esta perspectiva afeta as fundações epistemológicas da pesquisa etiológica e eventuais correlações entre espécies, conforme assevera que as variáveis etiológicas e nosológicas de nível profundo (genética 
e epigênese) e de nível descritivo (cérebro e comportamento) precisam ser pormenorizadas e discutidas em detalhes, para que resultados significativos emirjam.

O objetivo deste artigo é revisar e discutir criticamente as principais convergências e divergências presentes em ambos os níveis, no que concerne à depressão. Para tanto, iniciaremos com uma revisão da literatura recente dos tópicos de interesse. Incluímos nesta parte tanto um mapa conceitual (figura 1), quanto um mapa temático (figura 2), relativos à totalidade das publicações em modelos animais da depressão, indexadas no PubMed ou ISI em 2008-2009. Procedemos então com uma revisão de achados específicos em cérebro/comportamento e genética para definir os limites do conceito de depressão, tal como aplicado a humanos. Por fim, na última seção, apresentamos um algoritmo que sistematiza as principais perspectivas levantadas.

\section{Revisão Topográfica através de 'Data Mining': Principais Conceitos e Organização Temática dos Estudos em Modelos Animais de Depressão (2008-2009)}

Cobrindo o período de janeiro de 2008 a fevereiro de 2009 encontramos 73 publicações indexadas no PubMed ou ISI, tendo os modelos animais de depressão como parte de seu assunto central, o que sugere que um considerável número de cientistas aceita os modelos animais como representantes válidos da depressão humana. Apresentamos abaixo os principais conceitos no campo, assim como as suas principais associações: 
Figura 1: Principais conceitos do campo na atualidade

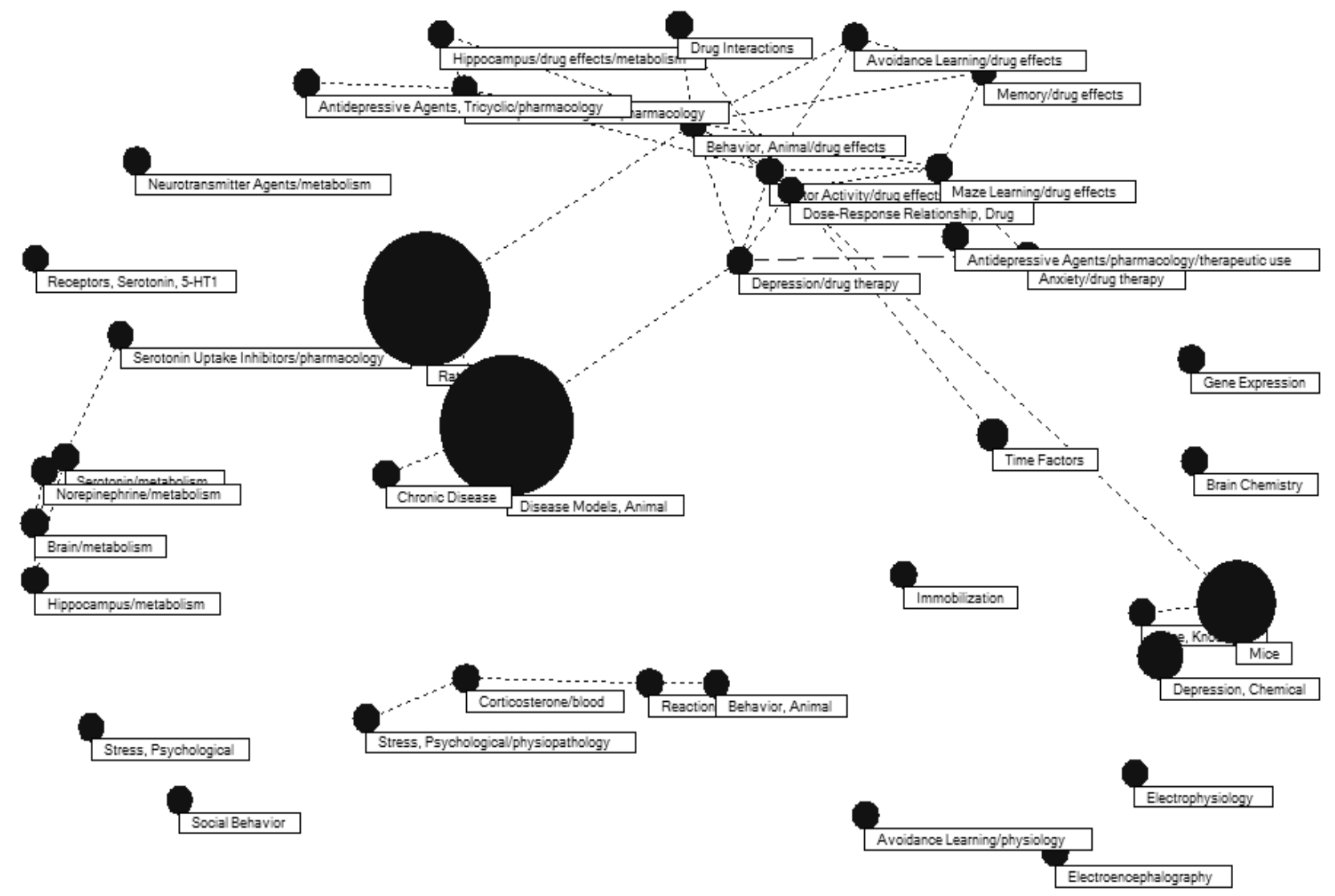

Tal como este mapa conceitual revela, os modelos animais são principalmente relacionados à depressão crônica; envolvem a utilização de ratos; em termos neurofisiológicos enfocam o papel da serotonina e, em termos comportamentais, o uso de imobilização referência ao teste de imobilização pela cauda em ratos - e aprendizado aversivo - alusão aos estudos voltados às tentativas de reverter estes aprendizados, como medida de reversão de um estado depressivo. A presença do estresse é proeminente, sugerindo sua associação com a depressão.

Paralelamente, é de se ter em vista que diversos agregados temáticos com modesta representatividade individual se relacionam em torno do desenvolvimento de antidepressivos, sob os seguintes tópicos: testes de terapias; testes de dosagens; efeitos sobre 0 aprendizado (em labirintos); aprendizado aversivo; efeitos na memória e no hipocampo; relação com a ansiedade; efeitos sobre o comportamento em geral. Segundo a nossa hipótese, isto reflete uma grande influência da indústria farmacêutica sobre os estudos e, portanto, alerta-nos sobre a possibilidade de vieses experimentais, tais como a conhecida tendência de se privilegiar os estudos com 
resultados positivos, em detrimento de estudos de resultados negativos ou inconclusivos.

Tal como revelado em análise subseqüente com 'data mining', estes conceitos pertencem a estudos que podem ser divididos em sete tópicos principais.



Figura 2: O campo dividido tematicamente

A distribuição temática do campo revela a existência de tópicos agregados, os quais sugerem que diversos autores/laboratórios estejam trabalhando em mais de uma linha de pesquisa. Isto é particularmente notável em relação às respostas a modelos experimentais de estresse em função de perfis cerebrais ou genéticos diversos. Nossa hipótese é a de que diferentes testes de estresse representem variáveis dependentes em experimentos relacionados a variações genéticas deletérias (i.e. polimorfismos relacionados à depressão) e a maus funcionamentos cerebrais associados (i.e. disfunção cortical associada ao mesmo polimorfismo). 
Confirmando o que se aventou em relação à figura 1, o mapa sugere que a maioria dos estudos esteja relacionada ao desenvolvimento e avaliação de antidepressivos. É de se notar que 25 estudos tratam diretamente do tema, ao passo que praticamente todos os outros, de alguma forma se relacionam com tema.

Um último aspecto interessante é a proeminência do hipocampo. Segundo a nossa hipótese, isto ocorre não apenas em função da importância deste para a etiologia e manifestação da depressão, mas em face de uma tendência atual em se considerar que terapias que funcionam para a depressão geram aumentos pontuais da plasticidade cerebral, o que se dá, sobretudo, nesta estrutura límbica.

\section{Correlações Descritivas: do Humor Diminuído à Depressão Maior}

A principal evidência a favor da possibilidade de se estender o conceito de depressão a outras espécies é relativa à responsividade dos modelos animais utilizados para o teste de eficácia de drogas antidepressivas (DEUSSING, 2006). Especificamente, modelos de roedores demonstraram que antidepressivos podem reduzir a imobilidade e produzir uma alteração completa do comportamento de anedonia à luta contínua no teste de suspensão pela cauda, o qual constitui um famoso paradigma de estresse crônico (CRYAN, MARKOU et al., 2002; LIU, PEPRAH et al., 2003; CRYAN, MOMBEREAU et al., 2005).

Em segundo lugar, despontam associações relacionadas aos efeitos de traumas emocionais sobre a suscetibilidade à desordem. Por exemplo, a exposição prematura à separação materna aumenta o risco de hiperalgesia induzida pelo estresse, simulando os efeitos da síndrome do cólon irritável em ratos (COUTINHO, PLOTSKY et al., 2002) de maneira semelhante ao que ocorre em humanos sofrendo de depressão (GHIA, BLENNERHASSETT et al., 2007; MAUNDER e LEVENSTEIN, 2008); macacos separados prematuramente de suas famílias apresentam maior predisposição à emissão de comportamentos de tipo depressivo quando reunidos ao grupo (YOUNG, SUOMI et al., 1973), efeito o qual parece persistir por anos (HINDE e SPENCER-BOOTH, 1971) (este achado foi confirmado em estudo follow up por CAPITANIO, 1986). Em conjunto, estes achados remontam a famosas teorias etiológicas humanas, as quais associam fatores de risco genético com a presença de experiências críticas.

Dito isto, é importante notar que também existem evidências de que estes dados devem ser analisados com cautela; por exemplo, um estudo testando detalhadamente os efeitos do estresse prematuro em roedores mutantes chegou à conclusão de que tal paradigma se associa a manifestações que remontam à depressão; não obstante, concluiu também que isto pouco tem a ver com o paradigma 
comportamental sendo, pois, fundamentalmente determinado pelos efeitos da expressão destes genes mutantes (BRAW, MALKESMAN et al., 2008); outro experimento sugeriu que a simples exposição ao aroma de folhas verdes poderia ser suficiente para reverter os efeitos depressivos apresentados por roedores intensamente afetados por pelos mesmos, em face de estresse induzido (NAKATOMI, YOKOYAMA et al., 2008), sugerindo assim que apenas uma forma mais branda e transitória de desordem afete aqueles animais.

Finalmente, e de maneira tanto mais significativa, há um descompasso entre a depressão e o paradigma de estresse comumente utilizado em experimentos com animais. Por exemplo, experimentos de estresse induzido em mamíferos sugerem que a exposição duradoura ao mesmo gera depletação noradrenérgica central (NA) e aumento dos níveis séricos adrenérgicos (Ad) e noradrenérgicos, o que é um padrão que remonta àquele encontrado na depressão humana; não obstante, enquanto a razão NA/Ad encontra-se aumentada nesta última, ela se mostra diminuída nos modelos animais submetidos aos paradigmas de estresse crônico (LECHIN, VAN DER DIJS et al., 1996). Em outras palavras, o perfil neuroendócrino da depressão não pode ser reproduzido através de testes de estresse, os quais representam os principais paradigmas experimentais na modelagem da depressão humana em animais. Assim, é de se assumir que muitas das publicações alinhavadas não se pautem por um modelo de depressão animal em estrito senso, mas antes por um modelo de estresse, do qual as similaridades emergem em associação com as diferenças.

\section{Correlações Genéticas}

A hipótese de que poderiam ser estabelecidas correlações genéticas associadas ao risco de desenvolver depressão, em humanos e outras espécies, emergiu como hipótese consistente antes do surgimento da genômica, em associação com a perspectiva de que a depressão não é apenas fruto de contingências presentes em determinadas culturas, bem como não se reduziria a um subproduto da modernidade. As principais evidências neste sentido são provenientes de relatos de manifestações de depressão em tribos de caçadores coletores, tais como os !Kung (HOWELL, 1979) e os esquimós do estreito de Bering (AOUN e GREGORY, 1998). Em direção contrária, suporte adicional a esta perspectiva faz-se representado por descrições de estados de depressivos em animais selvagens, vivendo em seus habitats naturais, sobretudo no que se refere ao abandono materno (depressão anaclítica) (HARLOW, 1959; GOODALL, 1973).

Dando suporte biológico à associação sugerida deste modo, o principal eixo genético relacionado à depressão maior se relaciona à cascata molecular responsável pela síntese e transporte da 
serotonina, em relação ao que, a presença de uma ou mais cópias do alelo curto (5-HTTLPR) na região promotora do gene transportador do neurotransmissor (5-HTT) representa o achado mais consistente (KUMAKIRI, KODAMA et al., 1999; CASPI, SUGDEN et al., 2003; HOEFGEN, SCHULZE et al., 2005; OLSSON, BYRNES et al., 2005; SERRETTI, MANDELLI et al., 2005; LEVINSON, 2006; LAZARY, LAZARY et al., 2008).

Os alelos do 5-HTT são responsáveis pela síntese da transmembrana que ativa a recaptação da serotonina na célula pré-sináptica, sendo o polimorfismo 5-HTTLPR relacionado à menor sensibilidade a antidepressivos inibidores da recaptação seletiva de serotonina (ZANARDI, BENEDETTI et al., 2000). Mormente, a presença dos alelos curtos está associada à diminuição da atividade serotonérgica global em humanos (CAROLA, FRAZZETTO et al., 2008) e macacos Rhesus (CASPI, SUGDEN et al., 2003). É interessante notar que estes achados são contrários à existência de diferenças intrínsecas por força da presença de mutações recentes: "Acredita-se que um polimorfismo criado a partir de uma inserção/deleção na região regulatória do gene 5-HTT tenha sido introduzida no genoma há cerca de 40 milhões de anos, apresentando formas homólogas em chimpanzés, orangotango, gorila e outros macacos" (OLSSON, BYRNES et al., 2005, p. 868).

Por outro lado, é de se ter em vista que a depressão é relacionada à vulnerabilidade genética e não a um determinismo genético (CASPI, SUGDEN et al., 2003; LEVINSON, 2006) (gêmeos idênticos possuem correlação de $69 \%$ para a desordem; KENDLER, 1993). Esta vulnerabilidade, que não se confunde com determinismo, é capaz de explicar diversos achados, tais como a presença diminuída (mas não inexistente) de depressão entre grupos étnicos isolados, em relação às taxas presentes na sociedade ocidental (AHMED e BHUGRA, 2006), bem como o fato de que anomalias epigenéticas aumentam o risco de depressão em humanos (REYNOLDS, CARNEY et al., 1984; DE VANNA e RIGAMONTI, 1992; ALMEIDA, FLICKER et al., 2005; TSANKOVA, RENTHAL et al., 2007; CZESAK, LU et al., 2008).Com isto em mente, faz-se possível assumir que a depressão esteja de fato associada a fatores genéticos largamente replicados, tais como o 5-HTTLPR (CHOTAI, SERRETTI et al., 2003), sem que se possa assumir que estes fatores possuem verdadeira especificidade etiológica. Por exemplo, além de ser relacionado à depressão, este alelo curto do gene transportador da serotonina também foi consistentemente associado ao transtorno obsessivo-compulsivo (para uma metaanálise com mais de três mil casos: LIN, 2007), migrânea com áurea (BORRONI, BRAMBILLA et al., 2005), ansiedade crônica (KATSURAGI, KUNUGI et al., 1999; MURPHY, LI et al., 2001; SERRETTI, MANDELLI et al., 2005) e alcoolismo (HAMMOUMI, PAYEN et al., 1999; OLSSON, 
BYRNES et al., 2005; PINTO, REGGERS et al., 2008), enquanto outras associações permanecem em discussão (OLSSON, BYRNES et al., 2005).

Este fato, associado à perspectiva de que alguns dos traços comportamentais mais paradigmáticos da depressão não são exclusivos da mesma (i.e. evitação social, anedonia) leva-nos a propor que seria mais sensato dizer que o que se estende a outras espécies é tanto menos a depressão e tanto mais o humor diminuído, - qual em humanos faz-se presente sob diversas combinações nosológicas e múltiplas desordens.

É razoável assumir que os diversos fatores genéticos que contribuem para a fisiopatia da depressão não o fazem de maneira determinística, mas antes contribuem para a consolidação estrutural de vias afetivas mais suscetíveis, as quais, em interação com variáveis extrínsecas, levarão à depressão, migrânea com áurea, transtorno obsessivo-compulsivo e outras desordens complexas. Dando suporte a esta idéia, um estudo recente mostrou que a presença de uma ou mais cópias do polimorfismo 5-HTTLPR se relaciona à atenção seletiva aumentada a estímulos incondicionados aversivos (no caso, aranhas) (OSINSKY, REUTER et al., 2008), o qual é um traço comum a várias desordens, enquanto outro estudo sugeriu que a presença destes alelos está associada à intensificação das respostas ao estresse (GOTLIB, JOORMANN et al., 2008).

Assim, alinhavando todos estes fatores, é de se dizer que a depressão humana faz-se única posto que se associa a uma inversão da relação NA/ad típica do estresse (e dos modelos animais de depressão), ao mesmo tempo em que emerge em um contexto em que diversas desordens colaterais representam vias alternativas à manifestação do fenômeno clínico, o qual não se reduz a nenhum achado ou grupo de achados de nível profundo, dada a vasta associação destes a outras tantas desordens tipicamente humanas.

Desordens afetivas e/ou mentais são sempre diagnosticadas pela exclusão de outras possíveis causas para os sintomas manifestos. Este é um ponto chave na distinção psicopatológica entre humanos e todas as outras espécies, assim como um ponto chave na distinção entre a depressão humana e animal. Um paciente supostamente sofrendo de depressão que manifesta episódios maníacos costuma ter seu diagnóstico trocado para transtorno bipolar; um paciente inicialmente sofrendo de ansiedade crônica, que passa a manifestar longos períodos de humor diminuído poderá ser rediagnosticado como portador de depressão; e assim por diante. No final das contas, estas relações laterais de tipo etiológico e nosográfico representam o aspecto mais marcante da psicopatologia humana.

Abaixo apresentamos um algoritmo ilustrando esta idéia: 


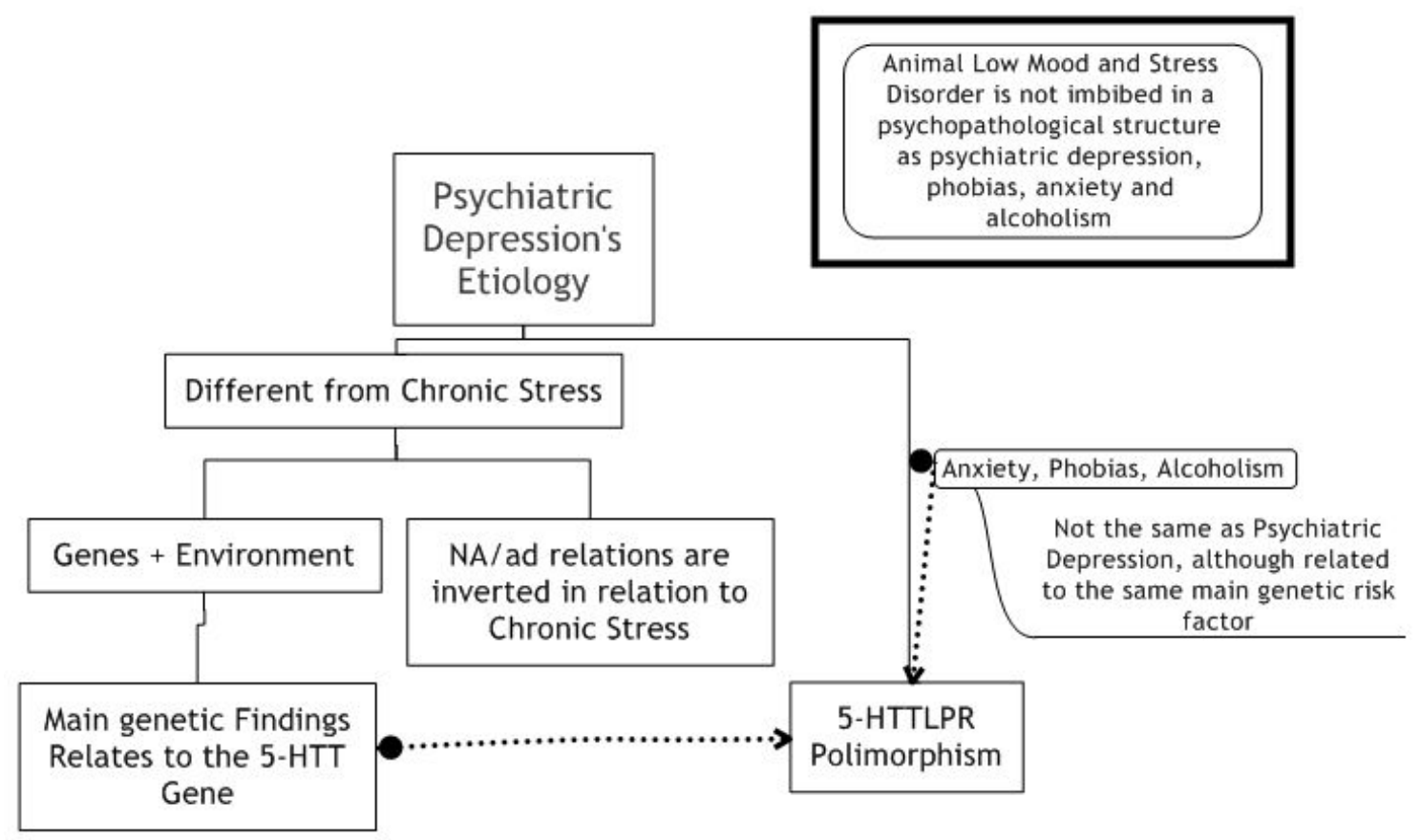

Figura 3: A depressão enquanto uma desordem que emerge de uma estrutura psicopatológica, onde a presença de fatores comuns não assevera unidades nosográficas idênticas

\section{Conclusões}

Como resposta à questão que motivou a elaboração deste artigo, podemos dizer que não há evidências de que se possa assumir uma relação forte entre a depressão humana e manifestações de humor diminuído em outras espécies, ao mesmo tempo em que se sobressai a inadequação do modelo de estresse característico dos estudos com animais, para a modelagem da depressão humana.

A depressão humana representa um 'ponto de chegada' tanto em nível distal quanto proximal, ao passo que cada unidade nosográfica representada no âmbito da psicopatologia adquire suas peculiaridades estruturalmente. Neste sentido, a depressão só pode ser concebida desde um universo de possibilidades representado por desordens alternativas, com as quais compartilha fatores em nível genético, orgânico e sintomatológico, a despeito da presença de sintomas típicos da depressão humana em outras espécies e, mais amplamente, do papel estratégico dos modelos animais.

\section{Referências Bibliográficas}

AHMED, K.; BHUGRA, D. Diagnosis and management of depression across cultures. Psychiatry [S.I.], v. 5, n. 11, p. 417-419, 2006. 
ALMEIDA, O. P. et al. Contribution of the MTHFR gene to the causal pathway for depression, anxiety and cognitive impairment in later life. Neurobiology of Aging [S.I.], v. 26, n. 2, p. 251-257, 2005.

AOUN, S. L.; GREGORY, R. J. Mental Disorders of Eskimos Seen at a Community Mental Health Center in Western Alaska. Psychiatr Serv [S.I.], v. 49, n. 11, p. 1485-1487, November 1, 19981998.

BORRONI, B. et al. Functional serotonin 5-HTTLPR polymorphism is a risk factor for migraine with aura. Journal of Headache and Pain [S.I.], v. 6, n. 4, p. 182-184, 2005.

BRAW, Y. et al. Withdrawal emotional-regulation in infant rats from genetic animal models of depression. Behavioural Brain Research [S.I.], v. 193, n. 1, p. 94-100, 2008.

CAROLA, $V$. et al. Identifying Molecular Substrates in a Mouse Model of the Serotonin Transporter $\times$ Environment Risk Factor for Anxiety and Depression. Biological Psychiatry [S.I.], v. 63, n. 9, p. 840846, 2008.

CASPI, A. et al. Influence of Life Stress on Depression: Moderation by a Polymorphism in the 5-HTT Gene. Science [S.I.], v. 301, n. 5631, p. 386-389, July 18, 20032003.

CHOTAI, J. et al. Gene-environment interaction in psychiatric disorders as indicated by season of birth variations in tryptophan hydroxylase (TPH), serotonin transporter (5-HTTLPR) and dopamine receptor (DRD4) gene polymorphisms. Psychiatry Research [S.I.], v. 119, n. 1-2, p. 99-111, 2003.

COUTINHO, S. V. et al. Neonatal maternal separation alters stressinduced responses to viscerosomatic nociceptive stimuli in rat. Am J Physiol Gastrointest Liver Physiol [S.I.], v. 282, n. 2, p. G307316, February 1, 20022002.

CRYAN, J. F. et al. Assessing antidepressant activity in rodents: recent developments and future needs. Trends in Pharmacological Sciences [S.I.], v. 23, n. 5, p. 238-245, 2002.

The tail suspension test as a model for assessing antidepressant activity: Review of pharmacological and genetic studies in mice. Neuroscience \& Biobehavioral Reviews [S.I.], v. 29, n. 4-5, p. 571-625, 2005.

CZESAK, M. et al. DNA methylation at 5-HT1A receptor promoter C(1019)G polymorphism CpG sites in schizophrenia and depression. J ournal of Affective Disorders [S.I.], v. 107, n. Supplement 1, p. S74-S74, 2008.

DE VANNA, M.; RIGAMONTI, R. Oral S-adenosyl-L-methionine in depression. Current Therapeutic Research [S.I.], v. 52, n. 3, p. 478-485, 1992.

DEUSSING, J. M. Animal models of depression. Drug Discovery Today: Disease Models [S.I.], v. 3, n. 4, p. 375-383, 2006. 
DIAS, A. M. et al. Depression Across the Species. Bentham Open Psychiatry J ournal [S.I.], v. 3, p. 33-38, 2009.

GHIA, J.-E. et al. Vagus nerve integrity and experimental colitis. Am J Physiol Gastrointest Liver Physiol [S.I.], v. 293, n. 3, p. G560567, September 1, 20072007.

GOODALL, J. The behavior of chimpanzees in their natural habitat. American J ournal of Psychiatry [S.I.], n. 130, p. 1-11, 1973.

GOTLIB, I. H. et al. HPA Axis Reactivity: A Mechanism Underlying the Associations Among 5-HTTLPR, Stress, and Depression. Biological Psychiatry [S.I.], v. 63, n. 9, p. 847-851, 2008.

HAMMOUMI, S. et al. Does the Short Variant of the Serotonin Transporter Linked Polymorphic Region Constitute a Marker of Alcohol Dependence? Alcohol [S.I.], v. 17, n. 2, p. 107-112, 1999.

HARLOW, H. F. Love in Infant Monkeys. Scientific American [S.I.], v. 200, n. 6, p. 68-73, 1959.

HINDE, R. A.; SPENCER-BOOTH, Y. Effects of Brief Separation from Mother on Rhesus Monkeys. Science [S.I.], v. 173, n. 3992, p. 111118, July 9, 19711971.

HOEFGEN, B. et al. The power of sample size and homogenous sampling: Association between the 5-HTTLPR serotonin transporter polymorphism and major depressive disorder. Biological Psychiatry [S.I.], v. 57, n. 3, p. 247-251, 2005.

HOWELL, N. The demography of the Dobe !Kung. New York: Academic Press, 1979.

J OHN P. CAPITANIO, K. L. R. R. D. S. S. M. L. M. R. Long-term followup of previously separated pigtail macaques: group and individual differences in response to novel situations. Journal of Child Psychology and Psychiatry [S.I.], v. 27, n. 4, p. 531-538, 1986.

KATSURAGI, S. et al. Association between serotonin transporter gene polymorphism and anxiety- related traits. Biological Psychiatry [S.I.], v. 45, n. 3, p. 368-370, 1999.

KENDLER, K. S. P., N,; JOHNSON, L.; NEALE M.C.; MATHÉ, A. A. A pilot Swedish twin study of affective illness, including hospital- and population-ascertained subsamples. Arch Gen Psychiatry [S.I.], v. 50, n. 9, p. 699-700, 1993.

KUMAKIRI, C. et al. Study of the association between the serotonin transporter gene regulatory region polymorphism and personality traits in a Japanese population. Neuroscience Letters [S.I.], v. 263, n. 2-3, p. 205-207, 1999.

LAZARY, J. et al. New Evidence for the Association of the Serotonin Transporter Gene (SLC6A4) Haplotypes, Threatening Life Events, and Depressive Phenotype. Biological Psychiatry [S.I.], v. 64, n. 6, p. 498-504, 2008. 
LECHIN, F. et al. Stress versus depression. Progress in NeuroPsychopharmacology and Biological Psychiatry [S.I.], v. 20, n. 6, p. 899-950, 1996.

LEVINSON, D. F. The Genetics of Depression: A Review. Biological Psychiatry [S.I.], v. 60, n. 2, p. 84-92, 2006.

LEWIS, A. J. Melancholia: A Clinical Survey of Depressive States. J ournal of Mental Science [S.I.], v. 80, n. 329, p. 277-378, April 1, 19341934.

LIN, P.-Y. Meta-analysis of the association of serotonin transporter gene polymorphism with obsessive-compulsive disorder. Progress in Neuro-Psychopharmacology and Biological Psychiatry [S.I.], v. 31, n. 3, p. 683-689, 2007.

LIU, X. et al. Tail-suspension induced hyperthermia: a new measure of stress reactivity. J ournal of Psychiatric Research [S.I.], v. 37, n. 3, p. 249-259, 2003.

MAUNDER, R. G.; LEVENSTEIN, S. The Role of Stress in the Development and Clinical Course of Inflammatory Bowel Disease: Epidemiological Evidence. Current Molecular Medicine [S.I.], v. 8, p. 247-252, 2008.

MCKINNEY, W. T., JR.; BUNNEY, W. E., JR. Animal Model of Depression: I. Review of Evidence: Implications for Research. Arch Gen Psychiatry [S.I.], v. 21, n. 2, p. 240-248, August 1, 1969 1969.

MURPHY, D. L. et al. Genetic perspectives on the serotonin transporter. Brain Research Bulletin [S.I.], v. 56, n. 5, p. 487-494, 2001.

NAKATOMI, Y. et al. Serotonergic mediation of the antidepressant-like effect of the green leaves odor in mice. Neuroscience Letters [S.I.], v. 436, n. 2, p. 167-170, 2008.

OLSSON, C. A. et al. Association between 5-HTTLPR genotypes and persisting patterns of anxiety and alcohol use: results from a 10-year longitudinal study of adolescent mental health. Mol Psychiatry [S.I.], v. 10, n. 9, p. 868-876, 2005.

OSINSKY, R. et al. Variation in the Serotonin Transporter Gene Modulates Selective Attention to Threat. Emotion [S.I.], v. 8, n. 4, p. 584-588, 2008.

PARSHALL, A. M.; PRIEST, A. G. Nosology, Taxonomy and the Classification Conundrum of the Functional Psychoses. British J ournal of Psychiatry [S.I.], v. 162, p. 227-236, 1993.

PINTO, E. et al. The Short Allele of the Serotonin Transporter Promoter Polymorphism Influences Relapse in Alcohol Dependence.

Alcohol Alcohol. [S.I.], p. agn015, March 25, 2008.

REYNOLDS, E. $H$. et al. METHYLATION AND MOOD. The Lancet [S.I.], v. 324, n. 8396, p. 196-198, 1984. 
SERRETTI, A. et al. Social adjustment could be associated with the serotonin transporter gene in remitted patients with mood disorders and healthy subjects. Psychiatry Research [S.I.], v. 134, n. 2, p. 191-194, 2005.

TSANKOVA, $\mathrm{N}$. et al. Epigenetic regulation in psychiatric disorders. Nature Reviews Neuroscience [S.I.], v. 8, n. 5, p. 355-367, 2007.

YOUNG, L. D. et al. Early Stress and Later Response to Separation in Rhesus Monkeys. Am J Psychiatry [S.I.], v. 130, n. 4, p. 400-405, April 1, 19731973.

ZANARDI, R. et al. Efficacy of paroxetine in depression is influenced by a functional polymorphism within the promoter of the serotonin transporter gene [5]. Journal of Clinical Psychopharmacology [S.I.], v. 20, n. 1, p. 105-107, 2000.

\section{Endereço para correspondência}

Álvaro Machado Dias

Universidade de São Paulo, Instituto de Psicologia, Dep. de Neurociências e Comportamento, Av. Prof. Mello Moraes, 1721, Butantan, Cidade Universitária CEP 05508-030, São Paulo - SP, Brasil

Endereço eletrônico: alvaromd@usp.br

Recebido em: 11/09/2009

Aceito para publicação em: 19/10/2009

Acompanhamento do processo editorial: Deise Mancebo

\section{Notas}

* Publicado em português com autorização do Bentham Psychiatry J ournal. O texto é uma tradução de Alvaro Machado Dias do artigo Depression Across the Species, publicado originalmente no Bentham Psychiatry Journal, v. 3, p. 33-38, 2009, por Álvaro Machado Dias, Ana Karina Santos, Margareth Yuri Takeuchi e Cristina Harumi Adania.

** Psicólogo, Mestre em Psicologia, Bolsista CNPQ. 